\title{
Degrees of freedom effect on fragmentation in tandem mass spectrometry of singly charged supramolecular aggregates of sodium sulfonates
}

\author{
Serena Indelicato, ${ }^{\mathrm{a}, \mathrm{b}}$ David Bongiorno, ${ }^{\mathrm{a}, \mathrm{b}}$ * Sergio Indelicato, ${ }^{c}$ \\ Laszlo Drahos, ${ }^{d}$ Vincenzo Turco Liveri, ${ }^{a}$ Lilla Turiák, ${ }^{d}$ Karoly Vékey ${ }^{d}$ and \\ Leopoldo Ceraulo ${ }^{a, b}$
}

The characteristic collision energy (CCE) to obtain $\mathbf{5 0 \%}$ fragmentation of positively and negatively single charged noncovalent clusters has been measured. CCE was found to increase linearly with the degrees of freedom (DoF) of the precursor ion, analogously to that observed for synthetic polymers. This suggests that fragmentation behavior (e.g. energy randomization) in covalent molecules and clusters are similar. Analysis of the slope of CCE with molecular size (DoF) indicates that activation energy of fragmentation of these clusters (loss of a monomer unit) is similar to that of the lowest energy fragmentation of protonated leucine-enkephalin. Positively and negatively charged aggregates behave similarly, but the slope of the CCE versus DoF plot is steeper for positive ions, suggesting that these are more stable than their negative counterparts. Copyright (c) 2013 John Wiley \& Sons, Ltd.

Keywords: Supramolecular aggregates; MS/MS; Degrees of Freedom effect; fragmentation; activation energy

\section{Introduction}

The effect of molecular size on fragmentation of ions formed by electron ionization has been largely investigated already at the very beginning of organic mass spectrometry. ${ }^{[1-3]}$ This phenomenon can be explained on the basis of the quasi-equilibrium theory, meaning that the energy gained during the electron ionization ${ }^{[4-6]}$ or chemical ionization ${ }^{[7]}$ process is distributed statistically to all vibrational degrees of freedom (DoF). Thus, if the same amount of energy is spread over a larger number of DoF, less energy is conferred to each DoF. This results in slower fragmentation rates correlating with the size of the ions.

The appearance of soft ionization techniques such as fast atom bombardment $(\mathrm{FAB}){ }^{[8]}$ electrospray ionization $(\mathrm{ESI})^{[9]}$ and matrix assisted laser desorption ionization ${ }^{[10,11]}$ allowed collisioninduced dissociation (CID) and tandem mass spectrometry ${ }^{[12-15]}$ to be the most widespread method to fragment ions either for analytical purposes or to obtain structural information. A singly charged ion with $m / z \geq 2000$ also exhibits low fragmentation efficiency during CID demonstrating that the size effect also occurs in CID experiments. ${ }^{[16]}$ This indicates that collision energy (CE) conferred by the impact of target gas is likely to spread among all DoF in a short time (much less than the residence time in the collision cell, which is typically in the range of $\mu \mathrm{s}-\mathrm{ms})$. Therefore, in order to observe fragmentation, the parent ion needs more internal energy than that of the critical energy. The amount of excess energy required to observe fragments in the timescale of the mass spectrometric experiment has been referred to as the 'kinetic shift. ${ }^{[14]}$ The importance of this effect is generally recognized and has often been discussed. This is of particular importance, both from view of practical and fundamental applications, to study CE effects as a function of precursor ion size. However, so far, only few systematic studies concerning the quantitative relationship between CE and DoF have been reported in the literature. ${ }^{[17-22]}$ The relation between fragmentation energetics and molecular size for different type of polymers: polyethylene glycols (PEG), polytetrahydrofuran, and peptides has been reported by Memboeuf et al.. ${ }^{[21,23]}$ A good linear correlation between the characteristic CE (CCE, the CE corresponding to a survival yield of $50 \%^{[24-26]}$ ) and the mass of the ion has been observed independently of the type of instrument used. In particular, when the activation energy and entropy do not significantly depend on molecular mass (which is well satisfied for a given oligomer series), the linear correlation observed was excellent $\left(R^{2}>0.996\right)$. On the other hand for peptides, which have a range of activation energies (and entropies), the correlation was less accurate $\left(R^{2}=0.917\right){ }^{[21]}$ A good linear dependence of CCE with ion mass has also been found for singly and doubly lithiated polytetrahydrofuran. ${ }^{[23]}$ A recent systematic study of various homopolymers confirmed the linear correlation

* Correspondence to: David Bongiorno, Dipartimento di Chimica e Tecnologie Farmaceutiche, Università di Palermo, Italy. E-mail: dbongiorno@unipa.it

a Dipartimento di Scienze e Tecnologie Biologiche Chimiche e Farmaceutiche (STEBICEF), Università degli Studi di Palermo, V.le delle Scienze - Ed. 16 - 90128 Palermo, Italy

b Centro Grandi Apparecchiature - UniNetLab, Università degli Studi di Palermo, via F. Marini 14. I-90128 Palermo, Italy

C CQRC Laboratory, A.O.U.P. 'P. Giaccone', Via Del Vespro, 129. I-90127 Palermo, Italy

d Institute of Organic Chemistry, Research Centre for Natural Sciences, Hungarian Academy of Sciences, Pusztaszeri ut 59-67H-1025 Budapest, Hungary 
between the CCE and the precursor ion mass for the investigated polymers. The slopes of the linear trendlines were, however, significantly different for various homopolymers. The slope was found to decrease with the activation energy of dissociation, decreasing in the order of polyethers > polymethacrylates $>$ polyesters $>$ polysaccharides. This trend suggested that the slope of the CCE trendline is linearly proportional to the energy required for fragmentation. This also explains that cyclic structures have higher CCE values due to the additional energy needed for the ring-opening. ${ }^{[27]}$

All these investigations concerning the DoF effect on fragmentation are related to compounds characterized by covalently bound repeating units. To the best of our knowledge, the DoF effect has not been studied previously for noncovalent aggregates. This may be interesting in case of various organic or inorganic clusters and also biomolecular complexes. To shed some light on this subject, we decided to investigate the DoF dependence of the CCE of singly charged aggregates of amphiphilic substances such as sodium methanesulfonate $\left(\mathrm{MetSO}_{3} \mathrm{Na}\right)$, sodium $n$-butanesulfonate $\left(\mathrm{ButSO}_{3} \mathrm{Na}\right.$ ) and sodium $n$-octanesulfonate $\left(\mathrm{OctSO}_{3} \mathrm{Na}\right)$ (Fig. 1).

These species have been selected as typical representatives of noncovalent aggregate forming substances, ${ }^{[28]}$ more simple but structurally similar to the surfactant sodium bis(ethylhexyl)sulfosuccinate (AOT). AOT aggregates have been observed under ESI, ${ }^{[29-34]}$ fast atom bombardment, ${ }^{[35]}$ matrix assisted laser desorption ionization, ${ }^{[36]}$ and ToF-SIMS ${ }^{[37]}$ conditions both as positive and negative ions. Self-assembling sodiated AOT aggregates have also been investigated in vacuo by molecular dynamics simulation. ${ }^{[38,39]} \mathrm{MetSO}_{3} \mathrm{Na}$, ButSO ${ }_{3} \mathrm{Na}$ and $\mathrm{OctSO}_{3} \mathrm{Na}$, form analogous positively and negatively charged aggregates, under ESI conditions. ${ }^{[31,33]}$ This observation, together with theoretical studies ${ }^{[40]}$ suggests that the aggregation process is determined mainly by electrostatic interactions among head groups while the chain has little influence.

\section{Experimental section}

Methanesulfonic acid sodium salt, $\mathrm{MetSO}_{3} \mathrm{Na}$, $(\geq 98 \%)$, butanesulfonic acid sodium salt, ButSO $\mathrm{Na}_{3}(\geq 95 \%)$, 1-octanesulfonic acid sodium salt $\mathrm{OctSO}_{3} \mathrm{Na}$ (approx 98\%) were purchased from Sigma-Aldrich (Germany). Solvents used were LCMS grade from Sigma-Aldrich (Germany).
Mass spectrometry experiments were carried out using a quadrupole-time of flight high resolution LC/MS system (Waters Q-Tof Premier, Manchester, UK), which was equipped with an ESI.

In all ESI MS and ESI MS/MS experiments, the following common operating conditions were applied as follows: capillary voltage $3.5 \mathrm{kV}$ in $\mathrm{ESI}(+)$ and $3 \mathrm{kV}$ in ESI (-); sampling cone voltage: $60 \mathrm{~V}$, extraction cone voltage: $3.2 \mathrm{~V}$; ion guide: $1.2 \mathrm{~V}$, source temperature $90^{\circ} \mathrm{C}$; desolvation temperature $250^{\circ} \mathrm{C}$, cone gas flow $50 \mathrm{l} / \mathrm{hr}^{-1}$, desolvation gas flow $300 \mathrm{l} / \mathrm{hr}^{-1}$, mass range $50-1000 \mathrm{~m} / \mathrm{z}$ and collision gas: argon.

The ESI MS experiments were performed in positive and negative ion modes using $0.5 \mathrm{mM}$ solutions of each compound in water/methanol $(1: 1)$ that were infused at $10 \mu \mathrm{l} / \mathrm{min}^{-1}$ flow rate. ESI MS/MS measurements were performed using the same sample solutions, which were introduced directly into ESI source at $15 \mu \mathrm{l} / \mathrm{min}^{-1}$ flow rate.

The mixed solutions of hetero-oligomers $\left(\mathrm{MetSO}_{3} \mathrm{Na}\right.$, but $\mathrm{SO}_{3} \mathrm{Na}, \mathrm{OctSO}_{3} \mathrm{Na}$ ) were prepared using equimolecular starting solutions of each compound at a concentration $0.5 \mathrm{mM}$ in water/ methanol $(1: 1)$.

Leucine-enkephalin solution has been prepared using a water/ acetonitrile $(0,1 \%$ formic acid) solvent mixture at a concentration of $1 \mathrm{mg} / \mathrm{ml}^{-1}$. PEG samples with average molecular weights varying from 400 up to $1000 \mathrm{Da}$ were used at a $50 \mu \mathrm{M}$ concentration in methanol saturated with lithium bromide.

The survival yield curves for each analyte were obtained using the same experimental conditions as for ESI MS/MS experiments, except for the collision energies, which were varied by discrete values ranging from 5 to $115 \mathrm{~V}$ during the flow injection experiments. For each collision, energy ESI MS/MS spectrum was obtained by the average of 11 consecutive scans. The percent of each fragment was calculated dividing the counts of the corresponding peak to the sum of counts of all peaks including the precursor ion.

Experimental conditions were maintained constant through the complete set of measurements and each SY curve of positively and negatively singly charged aggregates was repeated three times.

\section{Results and discussion}

Within the investigated CE window, fragmentation of the selected noncovalent aggregates proceeds through consecutive and competitive losses of monomers and/or $n$-mers. This was<smiles>CCCCCCCCS(=O)(=O)[O-]</smiles><smiles>CCCCS(=O)(=O)[O-]</smiles>

Figure 1. Structures of sodium methanesulfonate $\left(\mathrm{MetSO}_{3} \mathrm{Na}\right)$, sodium buthanesulfonate (ButSO $\left.\mathrm{Na}\right)$, sodium octanesulfonate $\left(\mathrm{OctSO}{ }_{3} \mathrm{Na}\right)$. 
established through a careful analysis of the breakdown curves of parent daughter ions. ${ }^{[31]}$ There are practically no fragmentations involving cleavage of covalent bonds. ${ }^{[31,33]}$ Fragmentation efficiency can be described by the SY function defined according to the Equation 1

$$
S Y=\frac{I_{M}}{I_{M}+\sum I_{F}}
$$

where $I_{M}$ is the intensity of the ionized molecule and $\sum I_{F}$ is the sum of all fragment ions intensities.

The SY values versus the CE have been plotted for the singly charged noncovalently bound homo-oligomers of $\mathrm{MetSO}_{3} \mathrm{Na}$, ButSO $_{3} \mathrm{Na}, \mathrm{OctSO}_{3} \mathrm{Na}$, and of the hetero-oligomers of $\mathrm{MetSO}_{3} \mathrm{Na}$ ButSO ${ }_{3} \mathrm{Na}$, ButSO ${ }_{3} \mathrm{Na}-\mathrm{OctSO}{ }_{3} \mathrm{Na}$, MetSO ${ }_{3} \mathrm{Na}-\mathrm{OctSO}{ }_{3} \mathrm{Na}$. Graphs have been plotted for both positively and negatively charged supramolecular aggregates. CE dependent fragmentation of altogether 55 clusters have been studied, including the following species: $\left.\left[\left(\mathrm{MetSO}_{3}\right)_{n} \mathrm{Na}_{\mathrm{n}+1}\right]^{+} ;\left[\left(\mathrm{ButSO}_{3}\right)_{n} \mathrm{Na}_{\mathrm{n}+1}\right]^{+} ;\left[(\mathrm{OctSO})_{3}\right)_{n} \mathrm{Na}_{n+1}\right]^{+}$; $\left[\left(\mathrm{MetSO}_{3}\right)_{\mathrm{n}}\left(\mathrm{ButSO}_{3}\right)_{\mathrm{m}} \mathrm{Na}(\mathrm{n}+\mathrm{m})+1\right]^{+},\left[\left(\mathrm{MetSO}_{3}\right)_{\mathrm{n}}\left(\mathrm{OctSO}_{3}\right)_{\mathrm{m}} \mathrm{Na}(\mathrm{n}+\mathrm{m})\right.$ $\left.{ }_{+1}\right]^{+}$; $\left[\left(\mathrm{ButSO}_{3}\right)_{\mathrm{n}}\left(\mathrm{OctSO}_{3}\right)_{\mathrm{m}} \mathrm{Na}_{(\mathrm{n}+\mathrm{m})+1}\right]^{+}$in positive ion mode and $\left[\left(\mathrm{MetSO}_{3}\right)_{n} \mathrm{Na}_{n-1}\right]^{-} ; \quad\left[\left(\mathrm{ButSO}_{3}\right)_{n} \mathrm{Na}_{n-1}\right]^{-}, \quad\left[\left(\mathrm{OctSO}_{3}\right)_{n} \mathrm{Na}_{n-1}\right]^{-}$;


$(\mathrm{n}+\mathrm{m})-1]^{-} ;\left[\left(\mathrm{ButSO}_{3}\right)_{\mathrm{n}}\left(\mathrm{OctSO}_{3}\right)_{\mathrm{m}} \mathrm{Na}_{(\mathrm{n}+\mathrm{m})-1}\right]^{-}$in negative ion mode (with $n+m=6$ ). For positive ions, the results cover homo-oligomers with aggregation number $(\mathrm{n})$ ranging from 2 to 10 for $\mathrm{MetSO}_{3} \mathrm{Na}$, $\mathrm{ButSO}_{3} \mathrm{Na}$, OctSO $\mathrm{Na}_{3}$, whereas in negative ion mode, homoaggregates of $\mathrm{MetSO}_{3} \mathrm{Na}$ and $\mathrm{OctSO}_{3} \mathrm{Na}$ with $n=3-10$ and $\mathrm{ButSO}_{3} \mathrm{Na}$ with $n=3-7$ were observed. For hetero-oligomers, the $n+m$ value ranges from 2 to 6 both in positive and in negative ion modes.

The intensity of the precursor ion, and consequently the SY value, decreases with the $\mathrm{CE}$ applied. Results for $\mathrm{ButSO}_{3} \mathrm{Na}$ clusters $(n=3-5)$ in positive and negative ion modes are shown in Fig. 2. The shapes of SY curves as a function of CE can be well described by a sigmoid function. Figure 2 shows that the SY curves are shifted to higher collision voltage when the number of monomeric units is increased. This trend is closely analogous to that observed for covalently bound oligomers. ${ }^{[21,23,27]}$

To compare the behavior of different species (by type and number of monomers), we evaluated their CCE values. First of all, reproducibility of Q-Tof measurements was assessed. In order to determine repeatability, the SY curves of the $\mathrm{OctSO}_{3} \mathrm{Na}$ trimer were measured 10 times, both in positive and in negative ion modes. To verify interday reproducibility, the octanesulfonate trimer was measured at six different time points, in each case measuring the full SY curve and determining the CCE value. The results show that repeatability (relative standard deviation) of the CCE value was $4.2 \%$ in intraday experiments and $7.8 \%$ in interday ones, both in positive and negative ion modes. To avoid systematic errors, SY curves were acquired for each compound alternatively at low mass and high mass (e.g. SY of $\mathrm{OctSO}_{3} \mathrm{Na}$ with $n=2$ followed by $\mathrm{OctSO}_{3} \mathrm{Na}$ with $n=6$, then $\mathrm{OctSO}_{3} \mathrm{Na}$ with $n=3$, etc.).

The CCE values of all studied homoaggregates and heteroaggregates, both in positive and negative ion modes are shown in Fig. 3 as a function of the DoF covering a wide mass range from ca. 100 to $2100 \mathrm{Da}$. The number of DoF has been calculated by Equation 2

$$
D o F=(3 \times n)-6
$$

where $n$ is the number of atoms constituting the whole aggregate.

This mass range corresponds to $50-900$ DoF. The CCE values as a function of DoF for all positively charged aggregates can be
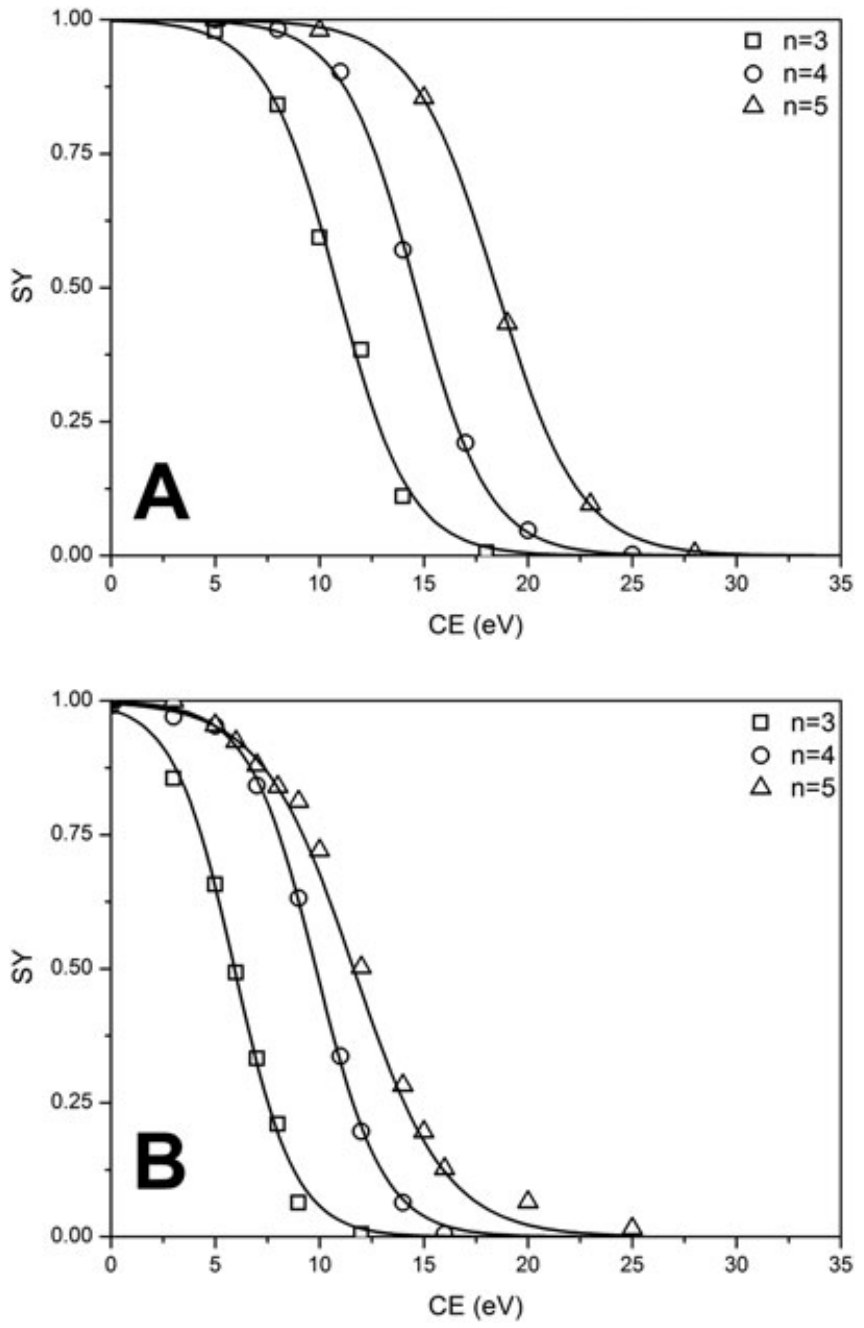

Figure 2. SY curves of $\mathrm{ButSO}_{3} \mathrm{Na}$ singly charged 3-mer, 4-mer, 5-mer (A) in positive ion mode and $\mathrm{B}$ ) in negative ion mode.



Figure 3. Characteristic collision energy as function of the degrees of freedom for positive $(\boldsymbol{\Delta})$ and negative ( $\boldsymbol{\square}$ ) alkanesulfonate aggregates. All compounds are singly charged. Trendlines (with slope and correlation coefficient) are also shown.

well described by a single linear trendline, characterized by a good linear fit $\left(R^{2}=0.975\right)$. It is worthwhile that the CCE values depend only on size (DoF). This implies that clusters with same 


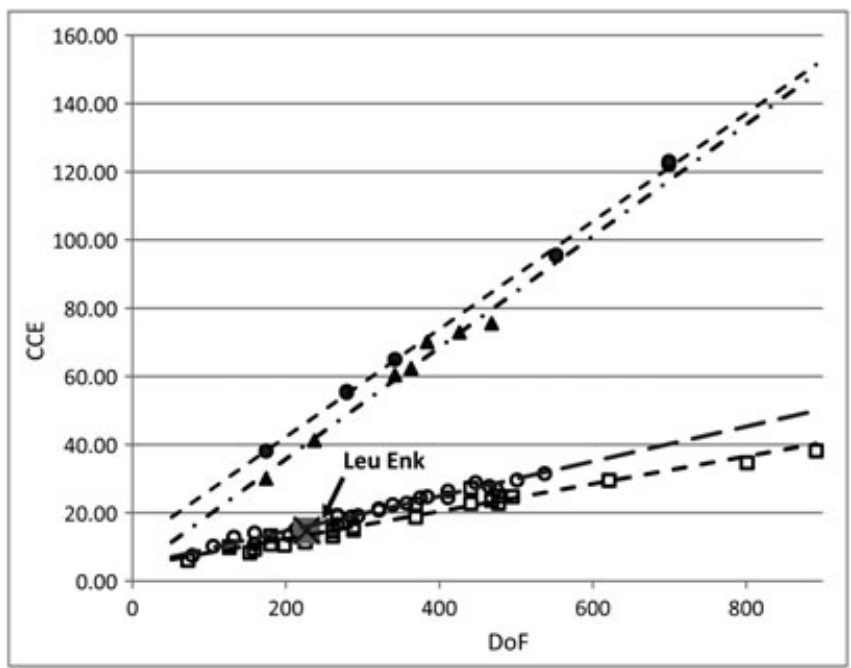

Figure 4. Characteristic collision energy values of lithiated PEGs taken from ref $21(\bullet)$, of lithiated polyethylene glycols obtained in the present work $(\boldsymbol{\Delta})$, of leucine-enkephalin measured in the present work $(X)$, and of positive $(O)$ and negative $(\square)$ alkanesulfonate clusters.

DoF but with different composition and aggregation number share the same CCE. A similar trend with a somewhat lower slope is observed for negatively charged aggregates (Fig. 3).

The present results on clusters may be compared with the behavior of PEGs shown in Fig. 4. This shows data on PEGs both measured in this study (triangles) and taken from the literature (filled circles ${ }^{[21]}$ ). Both data sets show a similar trendline and are numerically nearly superimposable. Note that the instrument in the present work was tuned according to standard procedures and not to scale the present results to those in the literature. This may suggest that similar type of instruments with roughly similar experimental conditions yield a similar degree of excitation (tandem mass spectra) under conventional tuning in different laboratories. As a further comparison, CCE of leucine-enkephalin has also been measured and is shown in Fig. 4.

It has been reported before ${ }^{[21,23,27]}$ that the linear trendline suggests that the studied series of compounds are all characterized by the same activation energy; and that the slope of the CCE versus DoF (or molecular mass) trendline closely relates to the activation energy of a series of oligomers. This may be expressed in a different way; that for two compounds having the same mass (or DoF) and the same charge state, a difference in CCE values represents a difference in activation energies. In the present case, the CCE value of protonated leucine-enkephalin practically overlaps with those of the studied clusters having the same DoF, suggesting that the respective activation energies are similar. The activation energy of the lowest energy fragmentation channel of leucine-enkephalin is $1.2 \mathrm{eV}$ (ranging from $1.14^{[41]}$ to $1.66^{[42]}$ with average value of $1.2 \mathrm{eV}^{[43]}$ ); this suggests that the activation energy of fragmentation for the studied clusters is similar, in the order of 1.2 (positively charged clusters) and $1.0 \mathrm{eV}$ (negatively charged clusters).

Comparing the slopes of the trendlines in Fig. 4 indicates that the slope for the studied clusters is much less than that of PEGs (by approximately a factor of three times); and it is also known that fragmentation of PEGs requires approximately $2.2-2.8 \mathrm{eV}^{[21]}$ activation energy. In qualitative terms, this corresponds well to the result based on comparison with leucine-enkephalin: the clusters have a much lower activation energy than those of PEGs.
The slope for positive clusters is about $20 \%$ higher than that of negative clusters, indicating that positive clusters have higher stability. This agrees well with relative ion stabilities of these aggregates indicated by both experimental ${ }^{[33]}$ and theoretical (molecular dynamics simulations ${ }^{[38]}$ ) data. Note that the intercept of the lines is usually a small positive value. Its explanation and physical relevance is unknown.

\section{Conclusions}

The experimental data shows a linear correlation between the CCE and the DoF of various noncovalent clusters of surfactants. This behavior is analogous to that observed for various synthetic oligomers, suggesting that the average energy required for the breaking of the interaction that leads to fragmentation does not change with cluster size (i.e. is independent of $n$ ). The analogy also implies that fragmentation of covalent molecules and noncovalent clusters follows the same scale law even though in one case bond cleavage, in the other, separation of noncovalent clusters take place. It is most tempting to rationalize it by fast randomization of internal energy both in covalent and noncovalent species. These observations are in line with the previous findings based on infrared multi-photon dissociation experiments, ${ }^{[39]}$ which also suggest fast spread of energy among vibrational DoF in noncovalent surfactant aggregates.

The slopes of the trendlines characterizing cluster fragmentation are much smaller than those of PEGs - this suggests that the corresponding activation energies are also much smaller than those characterizing PEGs (ca. $2.5 \mathrm{eV}^{[21]}$ ). In agreement with this observation, comparison with a well-studied peptide, leucineenkephalin suggests that its activation energy $\left(1.2 \mathrm{eV}^{[43]}\right)$ is very close to that of surfactant clusters. Positive clusters show a slightly higher slope than negative clusters, suggesting 10-20\% higher activation energy. These results correspond well with expectations of theoretical studies. ${ }^{[4]}$

\section{References}

[1] F. W. McLafferty, W. S. Pike. Metastable ion characteristics. II. variation of metastable ion abundances in mass spectra with vibrational degrees of freedom. J. Am. Chem. Soc. 1967, 89, 5951.

[2] F. W McLafferty, W. S. Pike. Metastable ion characteristics. III. structures of $\mathrm{C} \mathrm{H} 6 \mathrm{O}^{+}$ions in the mass spectra of aliphatic ketones. J. Am. Chem. Soc. 1967, 89, 5953.

[3] D. J. McAdoo, P. F. Bente. M. L. Gross, F. W. McLafferty. Product ions formed in mass spectral reactions. Org. Mass Spectrom. 1974, 9, 525.

[4] F. Bente, F. W. McLafferty, D. J. McAdoo, C. Lifshitz. Internal energy of product ions formed in mass spectral reactions. The degrees of freedom effect. J. Phys. Chem. 1975, 79, 713.

[5] F. W. McLafferty, F. Turecek. Interpretation of Mass Spectra. University Science Books: Mill Valley, CA, 1993.

[6] M. C. Natoli, L. Ceraulo, M. Ferrugia, L. Lamartina. Studies in organic mass spectrometry. Part 26. Unimolecular decomposition of orthomethoxy-substituted diphenylmethyl cations". Eur. Mass Spectrom. 1999, 5, 363.

[7] F. J. Winkler, F. O. Golacar, F. Mermoud, D. Stahl, T. Gäumann, A. Buchs. Degree-of-freedom activation effects in proton-transfer chemical ionization mass spectrometry of open-chain and cyclic alcohols and diols. Int. J. Mass Spectrom. Ion. Phys. 1983, 46, 321.

[8] M. Barber, R. S. Bordoli, R. D. Sedgwick, A. N. Tyler. Fast atom bombardment of solids as an ion source in mass spectrometry. Nature 1981, 293, 270.

[9] C. M. Whitehouse, N. Robert M. Yamashita, J. B. Fenn. electrospray interface for liquid chromatographs and mass spectrometers. Anal. Chem. 1985, 57, 675 . 
[10] M. Karas, F. Hillenkamp. Laser desorption ionization of proteins with molecular masses exceeding 10000 daltons. Anal. Chem. 1988, 60, 2299. doi: $10.1021 /$ ac902463q

[11] K. Tanaka, H. Waki, Y. Ido, S. Akita, Y. Yoshida, T. Yoshida. "Protein and polymer analyses up to $\mathrm{m} / \mathrm{z} 100000$ by laser ionization time-of flight mass spectrometry. Rapid Commun. Mass Spectrom. 1988, 2, 151. doi: $10.1002 / \mathrm{rcm} .1290020802$.

[12] F. W. McLafferty. Introduction and History. In Tandem Mass Spectrometry. F. W. McLafferty, (Ed). John Wiley: New York, 1983.

[13] R. G. Cooks, (Ed). Collision Spectroscopy. Plenum Press: New York, 1978.

[14] K. Levsen. Fundamental Aspects of Organic Mass Spectrometry. Verlag Chemie: NewYork, 1978.

[15] A. K. Shukla, J. H. Futrell. Tandem mass spectrometry: dissociation of ions by collisional activation. J. Mass Spectrom. 2000, 35, 1069.

[16] A. L. Burlingame, A. Dell, D. H. Russell. Mass spectrometry. Anal. Chem. 1982, 54, R363.

[17] A. R. Dongre, J. Jones, L. A. Somogyi, V. Wysocki. Influence of peptide composition, gas-phase basicity, and chemical modification on fragmentation efficiency: evidence for the mobile proton model. J. Am. Chem. Soc. 1996, 118, 8365.

[18] V. Bernshtein, I. Oref. Unimolecular dissociation of very large polyatomic molecules. J. Phys. Chem. 1994, 98, 136.

[19] J. Laskin, C. Lifshitz, (Eds). Principles of Mass Spectrometry Applied to Biomolecules. John Wiley \& Sons, 2006, i-xviii.

[20] J. L. Jones, A. R. Dongre, A. Somogyi, V. H. Wysocki. Sequence dependence of peptide fragmentation efficiency curves determined by electrospray ionization/surface-induced dissociation mass spectrometry. J. Am. Chem. Soc. 1994, 116, 8368.

[21] A. Memboeuf, A. Nasioudis, S. Indelicato, F. Pollreisz, A. Kuki, S. Kéki, O. F. Van den Brink, K. Vékey, L. Drahos. Size effect on fragmentation in tandem mass spectrometry. Anal. Chem. 2010, 82, 2294

[22] V. Gabelica, E. De Pauw. Internal energy and fragmentation of ions produced in electrospray sources. Mass Spectrom. Rev. 2005, 24, 566.

[23] Á. Kuki, L. Nagy, A. Memboeuf, D. László, K. Vékey, M. Zsuga, S. Kéki. Energy-dependent collision-induced dissociation of lithiated polytetrahydrofuran: effect of the size on the fragmentation properties. J. Am. Soc. Mass Spectrom. 2010, 21(10), 1753.

[24] C. Collette, L. Drahos, E. D. Pauw, K. Vékey. Comparison of the internal energy distributions of ions produced by different electrospray sources. Rapid Commun. Mass Spectrom. 1998, 12, 1673.

[25] F. Derwa, E. D. Pauw, P. Natalis. New basis for a method for the estimation of secondary ion internal energy distribution in 'soft' ionization techniques. Org. Mass Spectrom. 1991, 26, 117.

[26] X. H. Guo, M. C. Duursma, P. G. Kistemaker, N. M. M. Nibbering, K. Vekey, L. Drahos, R. M. A. Heeren. Manipulating internal energy of protonated biomolecules in electrospray ionization Fourier transform ion cyclotron resonance mass spectrometry. J. Mass Spectrom. 2003, 38, 597.

[27] A. Nasioudis, A. Memboeuf, R. M. A. Heeren, D. F. Smith, K. Vékey, L. Drahos, O. F. Van den Brink. Discrimination of polymers by using their characteristic collision energy in tandem mass spectrometry. Anal. Chem. 2010, 82, 2294.

[28] L. Ceraulo, G. Giorgi, V. Turco Liveri, D. Bongiorno, S. Indelicato, F. Di Gaudio, S. Indelicato. Mass spectrometry of surfactant aggregate. Eur. J. Mass Spectrom. 2011, 17, 525. doi: 10.1255/ejms.1
[29] G. Giorgi, L. Ceraulo, V. Turco Liveri. Surfactant self-assembly in the gas phase: bis(2-ethylhexyl)sulfosuccinate-alkaline metal ion aggregates. J. Phys. Chem. B 2008, 112, 1376-1382.

[30] G. Giorgi, E. Giocaliere, L. Ceraulo, A. Ruggirello, V. Turco Liveri. Spatially ordered surfactant assemblies in the gas phase: negatively charged bis(2-ethylhexyl)sulfosuccinate-alkaline metal ion aggregates. Rapid Commun. Mass Spectrom. 2009, 23, 2206.

[31] D. Bongiorno, L. Ceraulo, G. Giorgi, S. Indelicato, A. Ruggirello, V. Turco Liveri, Supramolecular aggregates in vacuum: positively monocharged sodium alkanesulfonate clusters. Eur. J. Mass Spectrom. 2010, 16, 151

[32] Y. Fang, A. Bennett, J. Liu. Multiply charged gas-phase NaAOT reverse micelles: formation, encapsulation of glycine, and collisioninduced dissociation. Int. J. Mass Spectrom., 2010, 293, 12.

[33] D. Bongiorno, L. Ceraulo, G. Giorgi, S. Indelicato, M. Ferrugia, A. Ruggirello, V. TurcoLiveri. Effects of the net charge on abundance and stability of supramolecular surfactant aggregates in gas phase. J. Mass Spectrom. 2011, 46, 195.

[34] Y. Fang, A. Bennett, J. Liu. Selective transport of amino acids into the gas phase: driving forces for amino acid solubilization in gas-phase reverse micelles. Phys. Chem. Chem. Phys. 2011, 13, 1466.

[35] P. A. Lyon, W. L. Stebbings, F. W. Crow, K. B. Tomer, D. L. Lippstreu, M. L. Gross. Analysis of anionic surfactants by mass spectrometry/mass spectrometry with fast atom bombardment. Anal. Chem. 1984, 56, 8.

[36] D. Bongiorno, L. Ceraulo, A. Ruggirello, V. Turco Liveri, E. Basso, R. Seraglia, P. Traldi. Surfactant self-assembling in gas phase: electrospray ionization- and matrix-assisted laser desorption/ionization-mass spectrometry of singly charged AOT clusters. J. Mass Spectrom. 2005, 40, 1618.

[37] S. A. Burns, P. L. jr Gardella. Determination of critical micelle concentration of aerosol-OT using time-of-flight secondary ion mass spectrometry fragmentation ion patterns. Langmuir 2009, 25, 11244

[38] G. Longhi, S. Abbate, L. Ceraulo, A. Ceselli, S. L. Fornili, V. Turco Liveri. A molecular dynamics study of structure, stability and fragmentation patterns of sodium bis(2-ethylhexyl)sulfosuccinate positively charged aggregates in vacuo. Phys. Chem. Chem. Phys. 2011, 13, 21423.

[39] G. Giorgi, L. Ceraulo, G. Berden, J. Oomens, V. Turco Liveri. Gas phase infrared multiple photon dissociation spectra of positively charged sodium bis(2-ethylhexyl) sulfosuccinate reverse micelle-like aggregates. J. Phys. Chem. B 2011, 115, 2282.

[40] D. Bongiorno, L. Ceraulo, G. Giorgi, S. Indelicato, V. Turco Liveri. Do electrospray mass spectra of surfactants mirror their aggregation state in solution? J. Mass Spectrom. 2011, 46, 1262

[41] K. G. Asano, D. J. Butcher, D. E. Goeringer, S. A. McLuckey. Effective ion internal temperatures achieved via boundary activation in the quadrupole ion trap: protonated leucine enkephalin. J. Mass Spectrom. 1999, 34, 691.

[42] J. Laskin. Energetics and dynamics of fragmentation of protonated leucine enkephalin from time- and energy-resolved surface-induced dissociation studies. J. Phys. Chem. A 2006, 10, 8554.

[43] J. Sztaray, A. Memboeuf, L. Drahos, K. Vékey. Leucine enkephalin-a mass spectrometry standard. Mass Spectrom. Rev. 2011, 30, 29.

[44] G. Longhi, S. L. Fornili, V. Turco Liveri, S. Abbate, D. Rebeccani, L. Ceraulo, F. Gangemi. Sodium bis(2- ethylhexyl)sulfosuccinate self-aggregation in vacuo: molecular dynamics simulation. Phys. Chem. Chem. Phys. 2010, 12, 4694 